\title{
EFFECT OF LIVING CONDITIONS ON THE DEVELOPMENT OF MULTIPLETS BORN IN THE DANZIG PROVINCE IN 1957-1971
}

\author{
M. KAMINSKA, A. KSIEZOPOLSKA-KACZOROWSKA, A. MAREK, \\ B. GUMKOWSKA-KAMINSKA, M. BOGDANOWICZ \\ Department of Pediatrics, Academy of Medicine, Danzig, Poland
}

The development of a total of 58 triplets, quadruplets, and quintuplets, born in the province of Danzig in the years 1957-1971, is analyzed. The examinations show that the pbysical development of multiplets in the first year of age is similar to that of singletons, irrespective of their social conditions. In the second year of age, bowever, multiplets with bad social conditions showed a much worse rate of development.

Only balf of the 56 children examined by a psychologist reached IQ norms, the others being on the verge of normalcy and mental deficiency, or even lower. Out of 30 school-age children, 16 bad difficulties in learning and 15 of these showed features of mental development deficiency.

According to the statistics of many countries, including Poland, multiple pregnancies presently occur much more frequently. This phenomenon may be the result of an ever more extensive application of hormonal contraceptives. According to other authors, however, an important role is played by such factors as maternal age (multiple pregnancies, particularly $\mathrm{MZ}$ ones, occur more frequently in 31-35 year-old women), disturbances of the menstrual cycle (also more frequent in the case of $\mathrm{MZ}$ pregnancies), and family inheritance, concerning first of all $\mathrm{D} Z$ pregnancies.

Stillbirths occur three times more frequently in multiple than in single pregnancies. Most frequently, perinatal deaths are caused by anoxia (44\%), birth trauma $(15 \%)$, and infections $(14 \%)$; a child born as the second or following neonate is particularly highly exposed to the effects of the aforesaid factors.

However, higher mortality is not the only important problem of multiple pregnancies. Lesions of the central nervous system, more frequently noted in children from multiple pregnancies and requiring preventive medical care, are of particular importance for the infant, family, and society.

Appreciating the complex nature of the factors shaping the fate of children from multiple pregnancies, the decision was taken to follow up the development of these children and to inquire into the influence of the environment in which they grow up on their physical and psychological development. The children born from triplet pregnancies in the Danzig province in 1957-1971 were particularly studied.

The investigation involved interviews, physical, psychological, and stomatological 
examinations, the assessment of dermatoglyphs, and a number of laboratory analyses, among which immunological and serological analyses (zygosity determination), karyotype, and the analyses of protein and lipid metabolism.

\section{RESULTS AND DISCUSSION}

The results are shown in the Tables.

Tables 1 and 2 give a general definition of the sample. It may be added that, by means of interviews, it was found that, in 15 families, multiple pregnancies had occurred also in the distant relatives of one or both parents. None of the mothers had used hormonal

Table 1. Multiple Births in Poland and the Danzig Province in 1957-1971

\begin{tabular}{lrr}
\hline \hline & Poland & Danzig province \\
\hline Twin births & 189,108 & 8,542 \\
Triplet births & 2,388 & 105 \\
Quadruplet births & 40 & 4 \\
Quintuplet births & 5 & 5 \\
Total multiple births & 191,541 & 8,656 \\
\hline Total births & $8,065,814$ & 414,554 \\
\hline
\end{tabular}

drugs in the period preceding the multiple pregnancy; 6 of them had abortions. Most of the pregnancies analysed were the third or fourth consecutive pregnancy of these mothers. Triplets occurred as first pregnancy only in 3 families.

In 7 cases the multiple pregnancies had a normal course. Complications occurred in 13 pregnancies, the most frequent being hemorrhages $(12$ cases) and toxemia (11 cases). Out of the 58 children examined, 22 were full-term and 36 premature deliveries, mostly in the eight month of pregnancy. Only half the children from multiple pregnancies were born by natural powers (see Table 3).

Serological analyses showed that only 1 set of triplets was MZ, while 13 were DZ, and $5 \mathrm{TZ}$. The quadruplets were $\mathrm{DZ}$ and the quintuplets quintovular.

Table 2. Multiplets Examined

\begin{tabular}{lllll}
\hline & Triplets & Quadruplets & Quintuplets & Total \\
& & & & \\
Children examined & 49 & 4 & 5 & 58 \\
Children deceased & 20 & 4 & 5 & 20 \\
Total & 69 & 4 & 1 & 24 \\
Families examineda & 22 & 1 & & \\
\hline
\end{tabular}

a In one family there were two triplet births, in four families all children died 
Table 3. Course of the Delivary

\begin{tabular}{lccl}
\hline \hline & $\begin{array}{l}\text { Full-term } \\
\text { delivery }\end{array}$ & $\begin{array}{l}\text { Premature } \\
\text { delivery }\end{array}$ & Procedure \\
& 10 & 23 & manual assistance \\
By natural powers & 4 & 3 & manual assistance \\
Breech presentation & 2 & 5 & $\begin{array}{l}\text { manual assistance } \\
\text { manual assistance } \\
\text { Footling presentation }\end{array}$ \\
$\begin{array}{l}\text { Transverse presentation } \\
\text { Adherent placenta }\end{array}$ & 2 & - & \\
Forceps & 2 & 2 & \\
Caesarean section & -3 & - & \\
Hemorrhage & 3 & & \\
\hline
\end{tabular}

The analysis of the general condition immediately after birth showed that in 45 of the 58 cases it was satisfactory. Respiratory troubles appeared in 7 children. Weights at birth were usually in direct proportion to the duration of the pregnancy. In some triplets the weight difference was however considerable, sometimes even in a $1: 2$ ratio.

Information on the living environment is given in Table 4. It may be added that the great majority of the families, both in the towns and in the country, had a poor living standard and their dwelling conditions were poor or average. Only 19 children lived in good conditions, 18 in average conditions, and 21 in poor conditions.

Living conditions are then put in relation with the physical development of the children (Table 5), also with respect to different stages (Table 6). In the first 6 months, physical development does not appear to be related to living conditions and does not essentially differ from the development of premature infants from single pregnancies. Around the 12th month of life most infants attained a normal body-weight, particularly those in good living conditions. The differences were more marked out in the 2 nd and 3 rd year of life, when three-fourths of the children in well-off families had a normal bodyweight. Under poor and average conditions, cases of underweight were found much more frequently when weight was $15 \%$ below the normal figure. The authors are of the opinion that the fact that normal body-weight was attained in the first year of life can be explained by the widespread good work of " D" (pediatric) outpatient clinics, and par-

Table 4. Social Environment of the Multiplets Examined

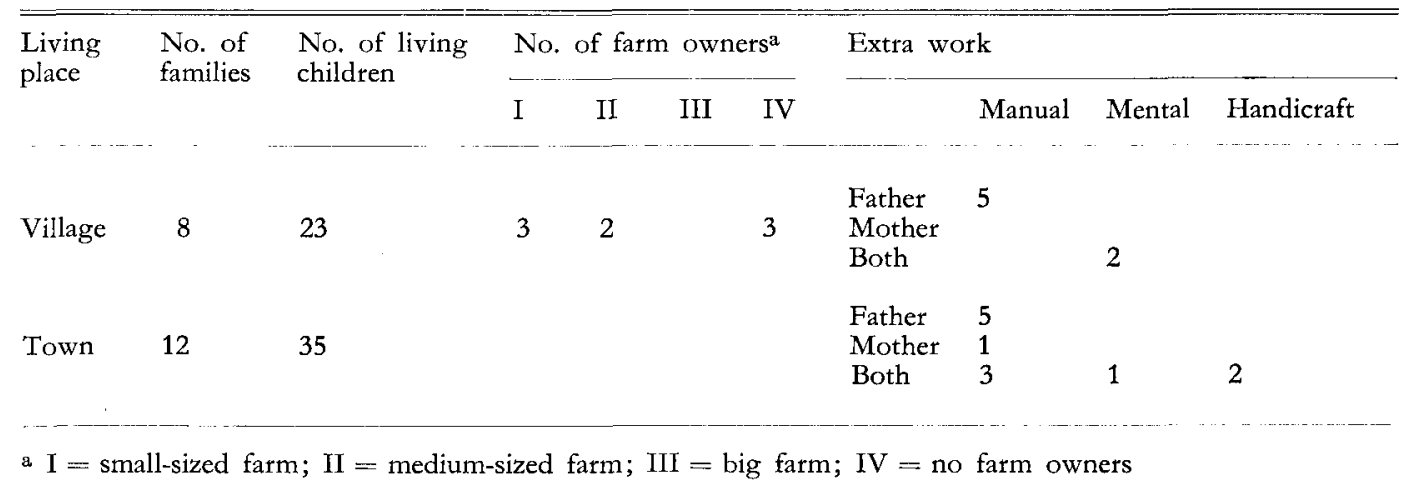


Table 5. Living Conditions and Pbysical Development of Multiplets

\begin{tabular}{|c|c|c|c|c|c|c|}
\hline \multirow[t]{2}{*}{ Living conditions } & \multicolumn{2}{|l|}{ Normal } & \multirow[t]{2}{*}{ Underweight } & \multirow{2}{*}{$\begin{array}{l}\text { Stature } \\
\text { deficiency }\end{array}$} & \multirow[t]{2}{*}{ Overweight } & \multirow{2}{*}{$\begin{array}{l}\text { Excessive } \\
\text { stature }\end{array}$} \\
\hline & Weight & Stature & & & & \\
\hline Good & 2 & 18 & 16 & 一 & 1 & 1 \\
\hline Average & 6 & 16 & 8 & 2 & 4 & - \\
\hline Poor & 6 & 17 & 15 & 4 & - & - \\
\hline
\end{tabular}

ticularly by the mode of nutrition.

When the development of children from multiple pregnancies is compared with that of their single-born siblings, it should be underscored that underweight was found exclusively in children from multiple pregnancies in 13 families, and in both triplets and singleborn siblings in only 5 families. It may be assumed that the poorer physical development of triplets was caused by the poor living conditions of the family, rather than by genetic factors.

Mental Development. Only one half of the 56 children examined by the psychologist had a normal IQ; 23 children were on the borderline of normalcy and mental deficiency, 6 of them achieving an IQ of 70 . Out of 30 children of school age, 16 found it difficult to learn at school: 15 of them were mentally deficient.

Diseases. It seems surprising to find that infectious diseases occurred somewhat more frequently in countryside children. (Low numbers do not however permit to find out whether this is a statistically significant fact.) Dental caries was equally frequent in rural and urban children. In total, out of 42 examined children, 5 had exclusively deciduous,

Table 6. Living Conditions and Body Weight of Multiplets

\begin{tabular}{|c|c|c|c|}
\hline \multirow{2}{*}{ Body weight } & \multicolumn{3}{|c|}{ Living conditions } \\
\hline & Good & Average & Poor \\
\hline \multicolumn{4}{|l|}{ At birth: } \\
\hline Normal & 6 & 9 & 7 \\
\hline Underweight & 9 & 16 & 11 \\
\hline Overweight & - & - & - \\
\hline \multicolumn{4}{|c|}{ 1st year of life: } \\
\hline Normal & 10 & 12 & 6 \\
\hline Underweight & 5 & 7 & 5 \\
\hline Overweight & - & - & 2 \\
\hline \multicolumn{4}{|c|}{ 2nd-3rd year of life: } \\
\hline Normal & 7 & 7 & - \\
\hline Underweight & 2 & 9 & 5 \\
\hline Overweight & - & - & - \\
\hline
\end{tabular}


30 mixed, and 7 permanent dentition. Dental caries was present in $91.4 \%$ of the children with deciduous dentition and in $89.1 \%$ of those with permanent dentition; $19 \%$ of the children had dentition defects, and $35 \%$ had a defective bite. Rickets, respiratory system diseases, diseases of the nasopharynx and of the alimentary tract, and anemia, were found more frequently in urban children, but rural children were those most often afflicted with skin diseases.

\section{CONCLUSIONS}

1. In the first year of life the development of multiplets in general does not deviate from the norms adopted for premature infants. In the present investigations it did not depend on living conditions.

2. At an age of more than one year the physical development was, as a rule, poorer in multiplets living under disadvantageous conditions. Those living under good conditions maintained a correct pace of development.

3. In poor living conditions, multiplets develop much worse than their single-born siblings living under the same conditions.

4. No significant difference was found between multiplets living in towns and those from villages.

5. In general, the satisfactory physical development of multiplets in the first year of life, irrespective of the environment in which they grow up, is probably the result of the proper work of the " $D$ " (pediatric) outpatient departments and of the good prophylaxis at that time.

The less favorable physical development of these children after the first year of age points to the need of a continued pediatric care, particularly for proper nutrition and continued prophylactic actions (protective inoculations, antirachitic action).

Dr. M. Kaminska, Department of Pediatrics, Academy of Medicine ul. Debinki 7, 80-211 Gdansk, Poland. 